This item was submitted to Loughborough's Research Repository by the author.

Items in Figshare are protected by copyright, with all rights reserved, unless otherwise indicated.

\title{
Modelling short crack propagation in a single crystal nickel-based superalloy using crystal plasticity and XFEM
}

PLEASE CITE THE PUBLISHED VERSION

https://doi.org/10.1016/j.ijfatigue.2020.105594

PUBLISHER

Elsevier

VERSION

AM (Accepted Manuscript)

\section{PUBLISHER STATEMENT}

This paper was accepted for publication in the journal International Journal of Fatigue and the definitive published version is available at https://doi.org/10.1016/j.ijfatigue.2020.105594.

LICENCE

CC BY-NC-ND 4.0

\section{REPOSITORY RECORD}

Zhang, Ping, Lu Zhang, Konstantinos Baxevanakis, Liguo Zhao, and Chris Bullough. 2020. "Modelling Short Crack Propagation in a Single Crystal Nickel-based Superalloy Using Crystal Plasticity and XFEM". Loughborough University. https://hdl.handle.net/2134/11969091.v1. 


\title{
Modelling Short Crack Propagation in a Single Crystal Nickel- based Superalloy using Crystal Plasticity and XFEM
}

\author{
P. Zhang ${ }^{1,2}$, L. Zhang ${ }^{3}$, K.P. Baxevanakis ${ }^{2}$, L.G. Zhao ${ }^{2,3^{*}}$ and C. Bullough ${ }^{4}$ \\ ${ }^{1}$ School of Power and Energy, Northwestern Polytechnical University, Xi'an, 710129, China \\ ${ }^{2}$ Wolfson School of Mechanical, Electrical and Manufacturing Engineering, Loughborough \\ University, LE11 3TU, UK \\ ${ }^{3}$ College of Energy and Power Engineering, Nanjing University of Aeronautics and \\ Astronautics, Nanjing, Jiangsu, 210016, China \\ ${ }^{4}$ GE Power, Rugby, CV21 2NH, UK
}

*Corresponding Author: L.Zhao@Lboro.ac.uk, Tel: 00441509227799

\begin{abstract}
Short cracks appearing under fatigue conditions are of major concern for safety-critical components. In this paper, a computational approach based on crystal plasticity and extended finite element method is developed to predict the slip-controlled short crack growth in a single crystal nickel-based superalloy. The onset of fracture is controlled by cumulative shear strain of individual slip system and the direction of crack growth follows crystallographic slip plane. Simulations are carried out for [111] orientation at $24{ }^{\circ} \mathrm{C}$ and $650{ }^{\circ} \mathrm{C}$, and the results confirm the capability of this approach in predicting the tortuous crack path and irregular propagation rate.
\end{abstract}

Keywords: Short crack propagation, Crystal plasticity, Extended finite element method, Cumulative shear strain, Nickel-based superalloy 


\section{Introduction}

In "damage-tolerance" life assessment, components may contain defects in the form of cracks that are allowed to grow up to a critical length. Thus, this approach requires accurate information of fatigue crack initiation and propagation, especially the evolution of short cracks which occupies a majority portion of the total fatigue life. Numerous experiments showed that short cracks exhibit a propagation behaviour different from long cracks [1], having fluctuations in crack propagation rate [2] and being highly affected by the local microstructure [3]. In single crystals, the propagation of short cracks depends more on the crystallographic orientation $[4,5]$ and temperature [6] due to the absence of grain boundaries. Neu [7] reviewed the crack path in single-crystal nickel (Ni)-based superalloys under various thermal conditions, and cracks appeared to grow along crystallographic planes at room temperature but followed an initial modeI path before switching to crystallographic paths at high temperature. Similar findings were also reported for a single crystal Ni-based superalloy in [8].

In numerical simulations of crack initiation and propagation, the finite element method (FEM) is widely used, where the crack path is usually specified beforehand or predicted step by step through subdivision calculations. The Virtual Crack Closure Technique (VCCT) [9] and the Cohesive Zone Model (CZM) [10] are among the techniques used to simulate crack propagation. However, the predicted crack paths are highly sensitive to the mesh structure and need to be predefined [11]. Also, continuous remeshing is required throughout the simulations since the crack surfaces need to be aligned with the finite element edges, leading to a high computational cost. The Extended Finite Element Method (XFEM) is designed to overcome these disadvantages [12]. This approach relies on the introduction of enrichment functions into the standard FEM so that arbitrary discontinuous structures can be described. In this method, cracks are modelled in a mesh-independent way, without the introduction of predefined paths 
or remeshing requirements. The XFEM has been used to simulate the growth of both macrocrack $[13,14]$ and microcrack [15].

In the past few decades, various stress-, strain- and energy-based macroscopic fracture criteria have been developed to simulate crack growth in metals [16-20]. These phenomenological models aim to find relationships between the crack growth rate and fracture parameters, which have been proved to work well for long cracks. However, they do not consider crystallographic mechanism, which prevents them from capturing the tortuous paths and highly varying growth rates at the early stage of crack growth. Hence, models that use dislocation- or slip-based crystal plasticity $(\mathrm{CP})$ theory to describe the material behaviour have been recently developed $[21,22]$. These models incorporate microscopic fracture criteria and enable the calculation of the driving force for crack growth as well as the direction for the crack extension. Besides, experimental studies [23] have related the crack growth to the cumulative plastic strain, which was subsequently used as a criterion to predict crack growth in numerical investigations [24]. Such criterion was also used with a CP model and a remeshing technique to predict the crack path in a polycrystalline Ni-based superalloy [25]. Specifically, the crack grew along the slip trace corresponding to the maximum cumulative slip and extended to the grain boundary. However, the crack path was assumed unchanged within each grain, and did not represent the intragranular deflection of crack growth observed experimentally [26].

In other studies, $\mathrm{CP}$ was combined with adaptive remeshing to achieve either straight or zigzag paths based on single- or double-slip behaviour of the material [27-29]. The damage indicator used in these papers was a combination of normal stress, resolved shear stress, and shear strain of each slip system. The crack growth was along the direction with the greatest damage rather than crystallographic directions. However, this method has a high computational cost 
and also requires experimental validation. More recently, a mechanistic framework based on XFEM and CP was developed for microstructurally-sensitive cracks, using dislocation configurational stored energy and crystallographic trace as the damage criterion and the growth direction, respectively [30]. Compared with the former models, this framework showed a better capability to capture the cross-slip behaviour, alternating crack path and the variations in propagation rate in both single crystals and bicrystals. The work was further extended to HCP (hexagonal close packed), BCC (body centred cubic) and FCC (face centred cubic) polycrystals, and the results were in good agreement with experiments [31]. However, the approach could not predict crack deflection within grains for FCC crystals as observed experimentally [8].

So far, there is no existing work that can successfully capture the tortuous crack path and fluctuating growth rate for short cracks in FCC single crystals. Despite the capability of XFEM to describe cracks with high accuracy at a relatively low computational expense, it has not been combined with $\mathrm{CP}$ models to predict the short crack propagation. In this article, a computational approach that combines slip-based CP and XFEM was proposed. Specifically, the CP model was calibrated from low cycle fatigue experiments and then applied to crack growth simulations based on XFEM. By using a crystallographic damage criterion, crack growth paths were predicted in a Ni-based superalloy at room and high temperatures. Meanwhile, crack propagation behaviour was discussed by tracking the activities of slip systems. Furthermore, crack growth rates were also calculated and compared with the experimental data.

\section{Methodology}

\subsection{CP model}

The model is based on the large deformation and rate-dependent CP theory $[32,33]$. The total deformation gradient $\mathbf{F}$ is decomposed into elastic and plastic parts 


$$
\mathbf{F}=\mathbf{F}^{e} \mathbf{F}^{p},
$$

where $\mathbf{F}^{e}$ corresponds to the elastic distortion of lattice and $\mathbf{F}^{p}$ denotes the plastic shear of the material.

The plastic velocity gradient $\mathbf{L}^{p}$ in the intermediate (or unrotated) configuration is defined as the sum of the crystallographic slip rate $\dot{\gamma}^{\alpha}$ on all slip systems $\alpha$ [34]

$$
\mathbf{L}^{p}=\dot{\mathbf{F}}^{p} \mathbf{F}^{p-1}=\sum_{a} \dot{\gamma}^{\alpha} \mathbf{s}^{\alpha} \otimes \mathbf{m}^{\alpha}
$$

where $\mathbf{s}^{\alpha}$ and $\mathbf{m}^{\alpha}$ refer to the direction of shear slip and normal to the slip plane in the reference configuration respectively.

The elastic strain is defined as the Green-Lagrange strain tensor $\mathbf{E}^{e}$

$$
\mathbf{E}^{e}=\frac{1}{2}\left[\mathbf{F}^{e \mathrm{~T}} \mathbf{F}^{e}-\mathbf{I}\right]
$$

where $\mathbf{I}$ is the second-order identity tensor. The second Piola-Kirchhoff stress $\mathbf{S}$ is related to $\mathbf{E}^{e}$ according to

$$
\mathbf{S}=\mathbf{C}^{e} \mathbf{E}^{e}
$$

where $\mathbf{C}^{e}$ is the fourth-order elastic constant tenor. Then the resolved shear stress on the slip plane $\alpha$ is obtained as

$$
\tau^{\alpha}=\mathbf{S}:\left(\mathbf{s}^{\alpha} \otimes \mathbf{m}^{\alpha}\right)
$$

and the Cauchy stress can be calculated as

$$
\boldsymbol{\sigma}=\operatorname{det}\left(\mathbf{F}^{e}\right)^{-1} \mathbf{F}^{e} \mathbf{S} \mathbf{F}^{e \mathrm{~T}}
$$

The plastic shear rate of each slip system follows a power-law function [35] of the resolved shear stress $\tau^{\alpha}$ given as 


$$
\dot{\gamma}^{\alpha}=\dot{\gamma}_{0}\left(\frac{\tau^{\alpha}-\chi^{\alpha}}{g^{\alpha}}\right)^{n} \operatorname{sign}\left(\tau^{\alpha}-\chi^{\alpha}\right)
$$

where $\dot{\gamma}_{0}$ is the reference shear strain rate, $g^{\alpha}$ is the critical shear stress of the $\alpha^{\text {th }}$ slip system for isotropic hardening, $\chi^{\alpha}$ is the back stress for kinematic hardening and $\mathrm{n}$ is the rate sensitivity exponent. The initial value of $g^{\alpha}$ represents the initial slip resistance $g_{0}$, which is assumed to be the same for all slip systems.

The isotropic hardening is characterised by the evolution of the critical shear stress by [36]

$$
\dot{g}^{(\alpha)}=\sum_{\beta} h_{\alpha \beta} \dot{\gamma}^{(\beta)}
$$

where $h_{\alpha \beta}$ is the slip hardening modulus due to the self-hardening and latent hardening given by

$$
h_{\alpha \beta}=q_{\alpha \beta} h_{(\gamma)}
$$

In the above equation, the subscripts $\alpha$ and $\beta$ are the indices of slip systems. When $\alpha=\beta$, $q_{\alpha \beta}$ becomes $q_{\alpha \alpha}$ which represents the self-hardening constant; while $q_{\alpha \beta}(\alpha \neq \beta)$ stands for the latent hardening constant. Also, $h_{(\gamma)}$ is the self-hardening modulus proposed as [33]

$$
h_{(\gamma)}=h_{0} \operatorname{sech}^{2}\left|\frac{h_{0} \gamma}{\tau_{s}-\tau_{0}}\right| \text {, }
$$

where $h_{0}$ is the initial hardening modulus, $\tau_{0}$ is yield stress which equals the initial critical resolved shear stress, $\tau_{s}$ is the stage I stress which controls the limit of $g^{\alpha}$, and $\gamma$ is the cumulative shear strain on all slip systems, which is calculated as

$$
\gamma=\sum_{\alpha} \int_{0}^{t}\left|\dot{\gamma}^{\alpha}\right| d t
$$


The kinematic hardening is described by the evolution of back stress with slip according to the standard Armstrong-Frederick model [37]

$$
\dot{\chi}^{\alpha}=c \dot{\gamma}^{\alpha}-d \chi^{\alpha}\left|\dot{\gamma}^{\alpha}\right|
$$

where $c$ is the direct hardening modulus and $d$ is the dynamic recovery modulus.

The CP framework described above has been incorporated in ABAQUS/Standard multipurpose finite element software [38] as a user material subroutine (UMAT) [39], which was used in this study.

\subsection{Extended finite element method (XFEM) based on cohesive behaviour}

The XFEM is an extension of the conventional finite element method by introducing a framework of the partition of unity [12]. In XFEM, discontinuities can be contained in an element by enriching degrees of freedom with discontinuous functions. Normally, the singularity around the crack tip is described by near-tip asymptotic functions $F_{a}(x)$ and the crack surfaces are represented by discontinuous functions $H(x)$. Then, the approximate displacement vector $\mathbf{u}$ can be calculated as

$$
\mathbf{u}=\sum_{i=1}^{N} N_{i}(x)\left[\mathbf{a}_{i}+H(x) \mathbf{b}_{i}+\sum_{\alpha=1}^{4} F_{\alpha}(x) \mathbf{c}_{i}^{\alpha}\right]
$$

where $N_{i}$ is the conventional nodal shape functions, $\mathbf{a}_{i}$ is the standard nodal displacement vector for the continuous part, $\mathbf{b}_{i}$ is the nodal enriched displacement vector of the nodes cut by the crack, $\mathbf{c}_{i}^{\alpha}$ is the nodal enriched displacement vector of the nodes around the crack tip. When the traction-separation cohesive behaviour is combined with the XFEM framework, $F_{a}(x)$, which represents the near-tip asymptotic singularity, is not needed [40]. The jump function $H(x)$ is the Heaviside function used to mark the side of a crack as 


$$
H(x)=\left\{\begin{array}{rc}
1, & x \in \Omega^{+}, \\
-1, & x \in \Omega^{-},
\end{array}\right.
$$

where $\Omega^{+}$and $\Omega^{-}$are the two sides of the crack.

To represent the discontinuity and cohesive behaviour, a special type of nodes termed as "phantom" nodes are superimposed to the real nodes. As shown in Fig. 1, when the element is undamaged, each phantom node and its corresponding real node are tied together. If the element is damaged, the separation of the element will be based on a cohesive law. When the cohesive strength of the damaged element decreases to zero, which means the crack goes through the element, the phantom and the real nodes will be separated, and the element will become two elements containing both real and phantom nodes.

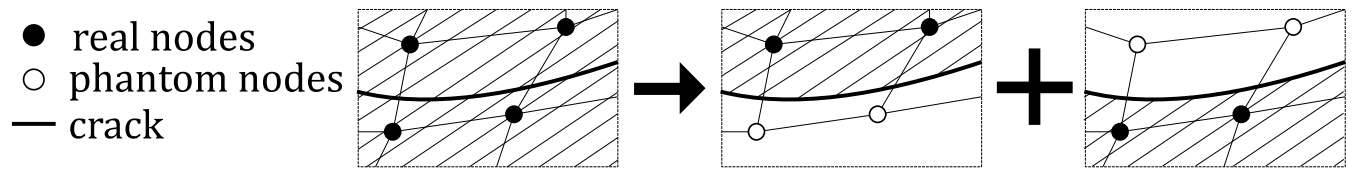

Fig. 1. Illustration of XFEM principle

XFEM has been successfully implemented in ABAQUS for over a decade. To specify damage criteria appropriate for crack propagation, a user damage subroutine (UDMGINI) is used, where the critical value and the vector normal to the crack growth direction are provided. During each computation increment, the onset of fracture is determined by the fracture value and normal direction vector averaged at the centroid of the element. The traction-separation behaviour will be activated when the fracture value is greater than 1.0 and the crack growth will be controlled by the normal direction vector.

\subsection{Crack growth criterion}


To physically capture the slip-controlled crack initiation and propagation, a damage criterion, including crack growth direction, needs to be proposed at the crystalline level. From the experimental observation [23] and existing numerical studies [24,25], crack propagation could be related to the accumulation of total strain or shear strain. In this work, because the slip-controlled crack paths were found in the in-situ SEM experiments, we assumed that the crack propagation was driven by the cumulative shear strain of individual slip system. Specifically, the individual cumulative shear strain (ICSS) was proposed as a damage criterion to reflect the contribution of each slip system, which is defined as

$$
I C S S_{\alpha}=\int_{0}^{t}\left|\dot{\gamma}^{\alpha}\right| d t
$$

Once initiated, the crack growth will be aligned with the crystallographic plane. Although XFEM seems straightforward to use, there are still some limitations as documented in ABAQUS (2018). Indeed, two limitations that mostly affect the crack propagation study in this paper are: i) only a single straight crack can be contained within an XFEM element and ii) crack deflection cannot be greater than 90 degrees. As a crack grows along a slip plane, it may have conflicting projected directions or sharp deflections, and hence, manual control was introduced when such situations happen. As shown in Fig. 2a, a normal crack would grow according to the projected direction and change its direction when the element ahead of the tip requires a different propagation path. However, under certain circumstances (depending on the predicted directions), results for the elements around the crack tip will produce contradictory projected directions which makes the crack unable to extend to any direction. For instance, as shown in Fig. 2b, the crack grows along the green direction and should re-enter the element with a predicted path along the red arrow (i.e., the blue dotted line). In this case, the calculation may stop or produce the wrong results regarding the crack path since only one single straight crack can be contained within an XFEM element. To avoid this issue, we force the crack to 
advance into the next element at a small angle and make it grow out of the contradictory zone by specifying the direction. It should be noted that in these cases, the crack fluctuates locally but shows an overall flat path macroscopically, hence the manual control does not essentially change the results. Similarly, when the crack is supposed to change its direction sharply, at an angle of larger than 90 degrees, the calculation will also either stop or generate a wrong result. As presented in Fig. 2c, the crack grows along the green direction and is supposed to deflect along the red direction, forming a sharp angle (blue dot line). In this situation, we make the crack change the direction through two consecutive changes of small angles rather than a sharp one. Once again, this interference will not affect the overall response as the transition only occurs at the turning point within 2 or 3 elements.

(a)

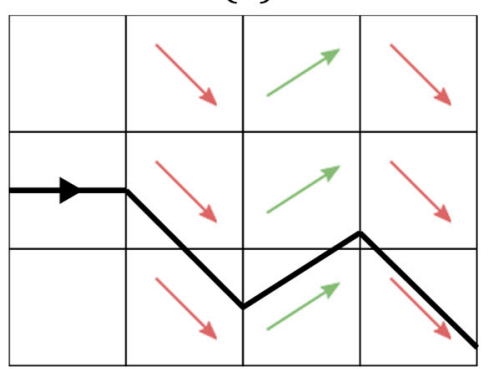

(b)

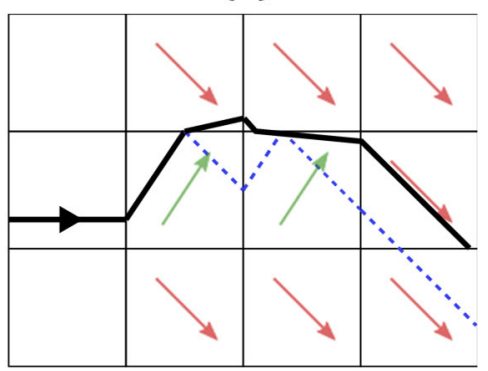

(c)

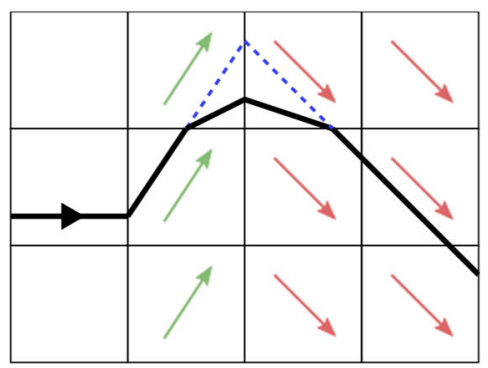

Fig. 2. Different crack-path scenarios: (a) normal case, (b) conflicting directions and (c) deflection angle greater than 90 degrees. The blue dashed line represents the abnormal paths and the black lines represent the path after manual control.

The above manual procedure was introduced through the user-defined damage subroutine (UDMGINI) of Abaqus, where the critical value and the vector normal to the crack growth direction are specified. When the abnormal situations illustrated in Fig. $2 \mathrm{~b}$ and $\mathrm{c}$ (blue dashed lines) happen, the element number ahead of the crack tip will be recorded and a new crack path will be specified for the recorded elements, leading to a smooth transition of crack growth path 
(black lines in Fig. 2b and c). More specifically, for the problem shown in Fig. 2b, the crack tried to turn back into the already cracked element (see row 2, column 2) according to the slipbased criterion, but was not possible due to the XFEM limitation. In this case, the direction of the normal vector will be kept unchanged to make sure the crack keeps going forward, but the magnitude of the vector will be multiplied by a small factor ( 0.1 in this work) to make the crack path close to the horizontal line before it could turn into the direction as predicted by the XFEM. To fix the problem shown in Fig. 2c, the normal vector for the element ahead of the crack tip was multiplied by a factor ( 0.1 in this work) to create a smaller angle of direction change.

\subsection{LCF experiment and CP model parameter calibration}

The material used in this study is a nickel-based single-crystal superalloy G-Ni 135SX (MD2), with a chemical composition of Ni-5.1Co-6.0Ta-8.0 Cr-8.1W-5.0Al-1.3Ti-2.1Mo-0.1Hf-0.1Si (in wt.\%). Single-crystal rods were prepared in [111] orientation and used to manufacture cylindrical dog-bone specimens for low cycle fatigue (LCF) experiments. The specimens had a gauge length of $13 \mathrm{~mm}$ and a diameter of $4.37 \mathrm{~mm}$ at the gauge section. LCF tests were performed at room temperature $\left(24^{\circ} \mathrm{C}\right)$ and $825^{\circ} \mathrm{C}$, using a servo-hydraulic testing machine, with the [111] orientation along the loading axis. All tests were strain-controlled, with a fully reversed $(R=-1)$ triangular waveform and a strain rate of $0.001 / \mathrm{sec}$. Three different strain amplitudes, $0.6 \%$ (30 cycles), $0.8 \%$ (30 cycles), and $1.0 \%$ (until complete fracture), were consecutively applied in each test.

The above experimental datasets were utilised to calibrate the CP model parameters presented in Section 2.1. To this aim, a single eight-node element (C3D8) was used to simulate the stressstrain response under low cycle fatigue. Based on TEM observations made in FCC crystals 
[41], there was no adequate evidence of the activation of cubic slip systems. So, only 12 equivalent $\{111\}<110>$ slip systems were considered in this work. The material properties used in all simulations were calibrated according to the following steps (Fig. 3): i) the elastic moduli for cubic crystals $\left(C_{11}, C_{12}, C_{44}\right)$ were determined from the monotonic part of cyclic loading curves, ii) the exponent $n$ and the reference shear strain rate $\dot{\gamma}_{0}$ were chosen by considering the rate-dependent sensitivity and numerical stability, iii) other parameters related to octahedral systems were determined by matching the [111] loading experiment data. Then, an optimisation process was used to minimise the overall distance of plastic strain between the experiment and simulation.

Here, we aimed to calibrate the CP model using the LCF test data which were conducted on cylindrical specimens. Therefore, a 3D model is appropriate and also more accurate for this purpose, as 2D simplification would cause a deviation in the model parameter calibration stage. Also, according to the ASTM standard (E606-04, 2004) [42], LCF tests are normally carried out under strain-controlled conditions. In this study, the LCF data were used mainly for CP model calibration. As long as the model was properly calibrated, it would not be a problem to simulate the material response under stress-controlled conditions (i.e. the in-situ SEM crack growth tests). 


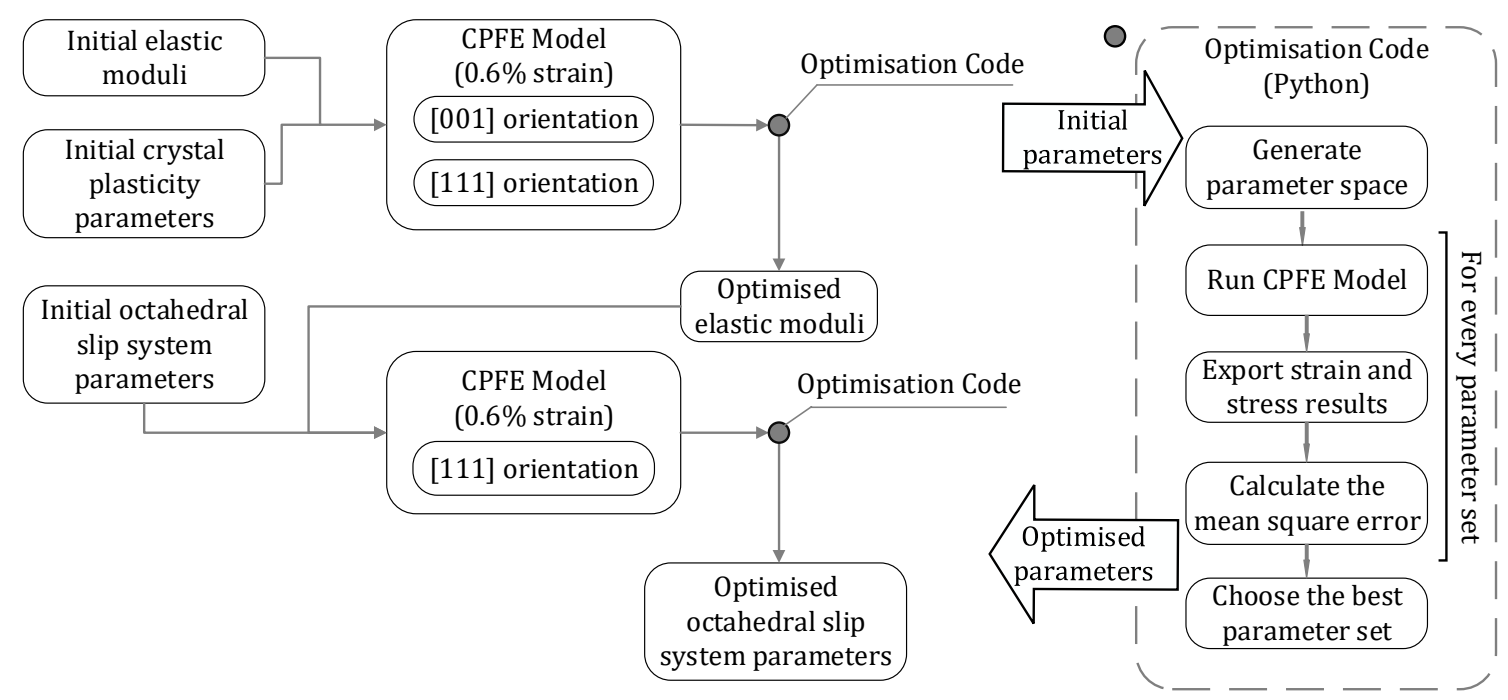

Fig. 3. CP model parameter calibration process

\section{Computational approach}

\subsection{Crack propagation model}

Fatigue tests on short crack propagation were performed by Zhang et al. [8] for alloy MD2 using an in-situ SEM approach. Dog-bone specimens with a gauge length of $5 \mathrm{~mm}$ and cross section of $2 \times 1 \mathrm{~mm}^{2}$ (Fig. 4a) were machined from the single-crystal rod of [111] orientation. A U-shape notch was produced in the middle section of the specimen, with a depth of $0.4 \mathrm{~mm}$ and a radius of $0.16 \mathrm{~mm}$ (Fig. $4 \mathrm{a}$ ). Tests were carried out in load-controlled mode at both room temperature and $650{ }^{\circ} \mathrm{C}$. The cyclic load had a sinusoidal waveform of $10 \mathrm{~Hz}$ frequency, with a peak stress of $680 \mathrm{MPa}$ and a load ratio of 0.1 . The SEM was operated in a vacuum condition with an accelerating voltage of $15 \mathrm{kV}$. The tests were paused at various intervals for SEM imaging in order to capture the crack length for later measurements.

To simulate the crack growth, a 2D plane strain model was developed for the notched region of the specimen in ABAQUS (Fig. 4b), covering an area of $2000 \times 5000 \mu \mathrm{m}^{2}$. This was an assumption made to facilitate the extremely time-consuming CP-XFEM simulations under fatigue loading conditions. It also reflected the situations of the in-situ SEM experiment for which 
the sample was relatively thick (thickness-width ratio $>0.5$ ) and the short fatigue cracks were found to propagate in a through-the-thickness manner (instead of surface cracking). However, it should be noted that the crystallographic slip of the material under plane strain condition behaves very similarly to that in an actual 3D model, therefore, the effect of plane-strain assumption on crack propagation is expected to be relatively small as the criterion for crack growth was based on the shear deformation of individual slip system. For XFEM simulation, a crack propagation area was specified near the notch root. Since we focus on the early stage of crack propagation, a dense mesh was created for this specified area that allows the crack to grow to a horizontal length of $110 \mu \mathrm{m}$. The elements are quadrilateral linear plane strain (CPE4) XFEM elements with an average size of $\sim 2.5 \mu \mathrm{m}$ (3850 elements). The rest of the domain was discretised into 360 CPE4 elements and 1713 triangular linear plane strain elements (CPE3). The XFEM result is generally considered mesh independent, but the manual control introduced in this work could locally affect the crack path. This mesh dependency is an inevitable consequence of the manual control process which was, however, essential to make the XFEM simulations continue in our study. To explore the mesh sensitivity, a denser mesh was recreated, with an average size of $\sim 1.25 \mu \mathrm{m}$ in the XFEM region. Simulations were carried out for the [111]-oriented specimen at $650{ }^{\circ} \mathrm{C}$, and the crack growth predicted by the two meshes followed almost the same path if we kept the amount of transition crack growth unchanged in the manual control process. In addition, a predefined crack was introduced to centre of the notch in the XFEM area to reflect the initiation of the crack observed experimentally (see the magnified section in Fig. 4b). To prevent rigid body movement, the bottom and the left sides of the model were constrained in their respective normal directions. 


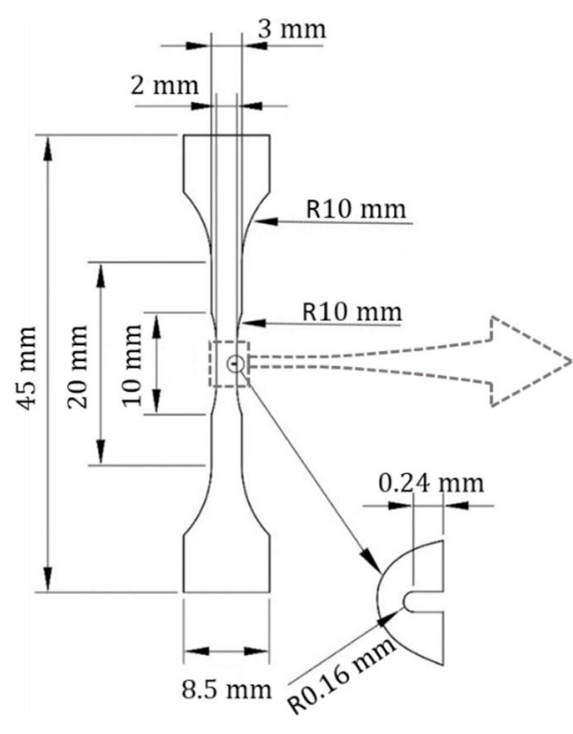

(a)

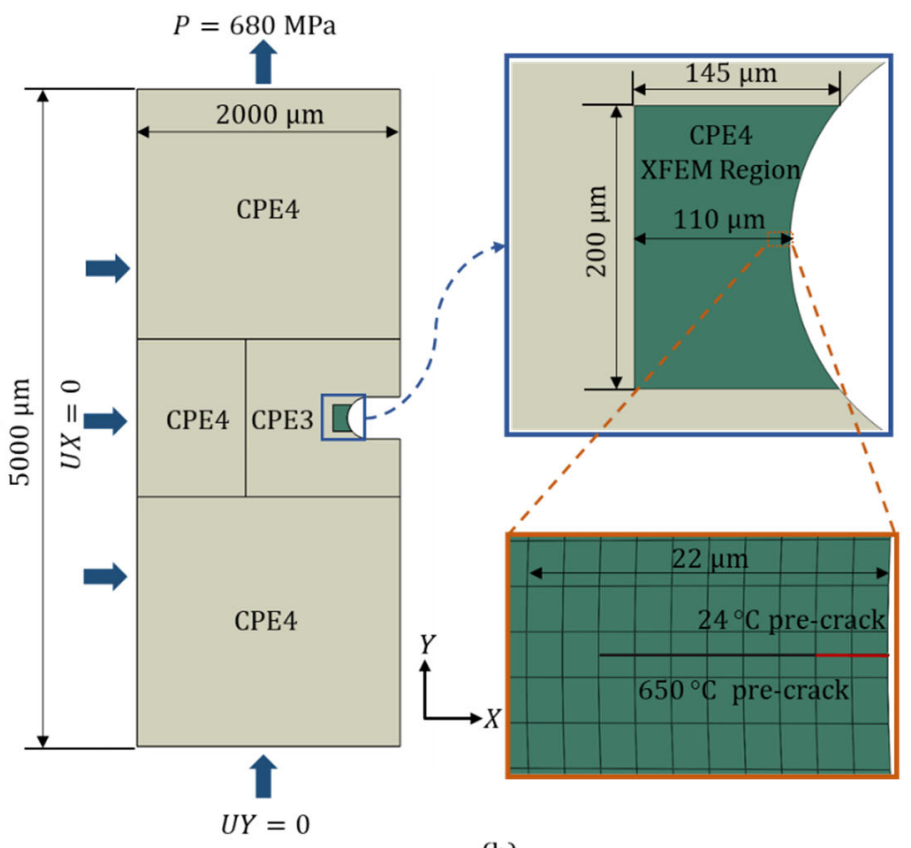

(b)

Fig. 4. (a) The geometry of specimens used in fatigue test and (b) boundary conditions and loading assignment description along with geometrical details of XFEM model for crack propagation simulation

\subsection{XFEM procedure}

In the ICSS criterion, the slip system with the highest ICSS value is chosen to be the representative slip system of an element. The fracture occurs in an element when its ICSS reaches a critical value, and its associated normal direction vector is considered as the normal of the corresponding slip plane (Fig. 5). In ABAQUS, multiple damage mechanisms can be defined, and the final damage behaviour of an enriched element is governed by the most critical one. Each mechanism contains a fracture criterion and a normal direction, and these parameters are calculated at the centroid of the element (averaged over the integration points). In this paper, four damage mechanisms with the same critical ICSS value were used to assess the possible crack growth along the four slip planes. The critical value of ICSS was chosen as 0.026 for $24{ }^{\circ} \mathrm{C}$ and 0.020 for $650{ }^{\circ} \mathrm{C}$ according to our observations in the simulations. Firstly, the distribution of ICSS for different slip systems was relatively stable at the crack tip after the first or 
second loading cycle. Secondly, the chosen critical value allowed us to obtain the crack growth rate within an acceptable level of computing times or number of loading cycles, i.e., 0.026 for $24{ }^{\circ} \mathrm{C}$. For $650{ }^{\circ} \mathrm{C}$, we proposed that the critical ICSS value was related to that for $24{ }^{\circ} \mathrm{C}$ through the critical resolved shear stress $\tau_{0}$ and the stage I stress $\tau_{\mathrm{s}}$ as expressed in the following equation

$$
\frac{I_{C S S_{24^{\circ} \mathrm{C}}}}{I C S S_{650^{\circ} \mathrm{C}}}=\frac{1}{2}\left(\frac{\tau_{0}^{24^{\circ} \mathrm{C}}}{\tau_{0}^{650^{\circ} \mathrm{C}}}+\frac{\tau_{\mathrm{s}}^{24^{\circ} \mathrm{C}}}{\tau_{\mathrm{s}}^{650^{\circ} \mathrm{C}}}\right) .
$$

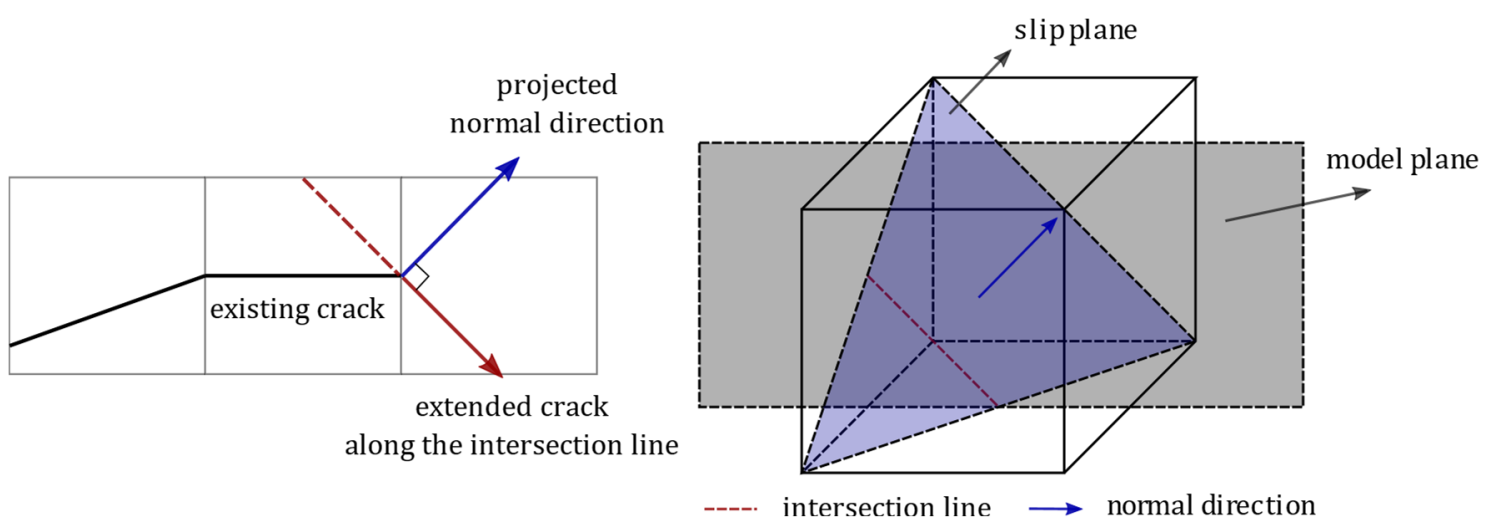

Fig. 5. Demonstration of crack direction definition: the normal direction of the slip plane is projected to the model plane then set to be the vertical vector of the enriched element, the crack goes along the intersection line of the model plan and the slip plane

An energy-based exponential function inside the Abaqus, which controls the damage evolution of enhanced element (XFEM element) based on cohesive behaviour, was used to describe the damage evolution of XFEM element. The damage evolution law describes the rate at which the cohesive stiffness degrades once the corresponding initiation criterion is met, i.e. how fast the element will be fully damaged. The energy-based exponential function contains two major parameters, the exponent and dissipated energy. In this study, the values were taken as 2 and 
0.001 to make sure the element, which contains the crack, is fully damaged at a fast but numerically stable speed. The maximum time increment was set as 0.01 second to avoid numerical instability and reduce the influence of partially damaged elements.

\section{Results and discussion}

\subsection{CP parameter calibration}

The CP model parameters were calibrated at both room $\left(24^{\circ} \mathrm{C}\right)$ and high temperatures $\left(825^{\circ} \mathrm{C}\right)$, and provided in Table 1. In addition, the parameters were also linearly interpolated in order to carry out the XFEM simulation of crack growth at $650^{\circ} \mathrm{C}$. Comparisons of the first hysteresis loop at $0.6 \%$ strain between the numerical and the experimental results are shown in Fig. 6a for $24^{\circ} \mathrm{C}$ and $825^{\circ} \mathrm{C}$, and the predicted results for $650^{\circ} \mathrm{C}$ are also provided. Very good agreement is observed at both $24{ }^{\circ} \mathrm{C}$ and $825^{\circ} \mathrm{C}$ conditions as the deviation of maximum stress level between experiments and simulations was less than $30 \mathrm{MPa}$. The simulation predicted slightly lower stress level at the elastic part, being less than $100 \mathrm{MPa}$ and having little influence on the crack propagation. Moreover, in Fig. $6 \mathrm{~b}$ the numerical results for stress evolution are compared to the experimental ones for $0.6 \%$ and $0.8 \%$ strains at $24{ }^{\circ} \mathrm{C}$ and $825^{\circ} \mathrm{C}$; while the prediction for $650{ }^{\circ} \mathrm{C}$ is also displayed. At both $24^{\circ} \mathrm{C}$ and $825^{\circ} \mathrm{C}$, the simulation can capture well the stress evolution at both strain ranges, and the deviations of maximum and minimum stress between experiments and simulations were less than $90 \mathrm{MPa}$.

Here, LCF tests were performed at $24{ }^{\circ} \mathrm{C}$ and $825^{\circ} \mathrm{C}$ only, while the in-situ SEM experiment was conducted at room temperature and $650{ }^{\circ} \mathrm{C}$ only (limited by machine capacity). These are the data currently available to us. To apply the $\mathrm{CP}$ model for crack propagation prediction at $650{ }^{\circ} \mathrm{C}$, we will have to use interpolation to work out the model parameters at $650{ }^{\circ} \mathrm{C}$ (as shown

in Table 1). The interpolation can introduce some inaccuracies for the strain-stress behaviour, 
but it won't affect the ICSS distribution at the crack tip too much since this behaviour is more dependent on the crystallographic orientation and the local crack path.

Table 1. Parameters of the CP model for MD2 at $24{ }^{\circ} \mathrm{C}, 825^{\circ} \mathrm{C}$ and $650{ }^{\circ} \mathrm{C}$

\begin{tabular}{cccc}
\hline Parameters & $24{ }^{\circ} \mathrm{C}$ & $825^{\circ} \mathrm{C}$ & $650{ }^{\circ} \mathrm{C}$ \\
\hline$C_{11} / \mathrm{MPa}$ & 174030 & 140000 & 147435 \\
\hline$C_{12} / \mathrm{MPa}$ & 77380 & 71250 & 72590 \\
\hline$C_{44} / \mathrm{MPa}$ & 118520 & 105650 & 108461 \\
\hline$n$ & 10 & 10 & 10 \\
\hline$\dot{\gamma}_{0} / \mathrm{sec}^{-1}$ & 0.00001 & 0.00001 & 0.00001 \\
\hline$h_{0} / \mathrm{MPa}$ & 173.5 & 150.4 & 155.4 \\
\hline$\tau_{s} / \mathrm{MPa}$ & 266.5 & 174.0 & 194.2 \\
\hline$\tau_{0} / \mathrm{MPa}$ & 216.8 & 165.0 & 176.3 \\
\hline$q_{\alpha \alpha}$ & 1 & 1 & 1 \\
\hline$q_{\alpha \beta}$ & 1 & 1 & 1 \\
\hline$c / \mathrm{MPa}$ & 200 & 200 & 200 \\
\hline$d$ & 2 & 2 & 2 \\
\hline
\end{tabular}

(a)

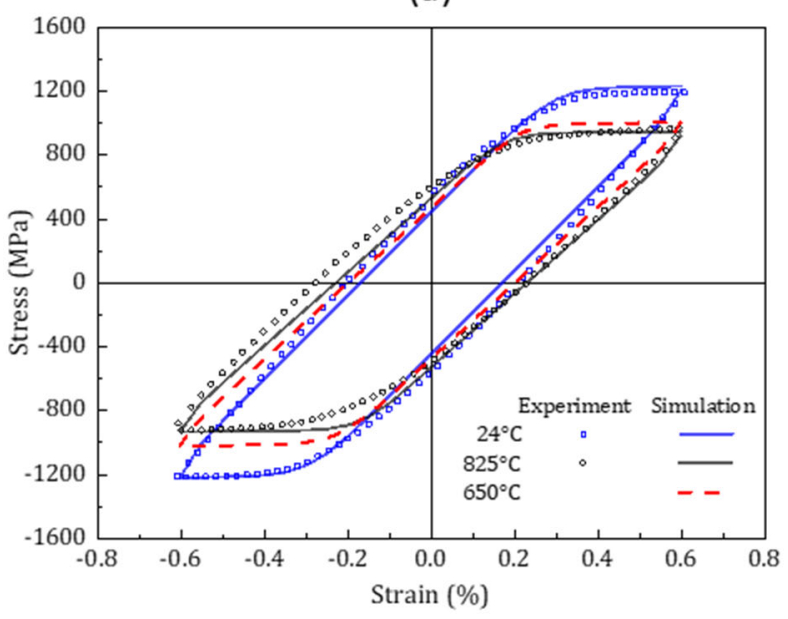

(b)

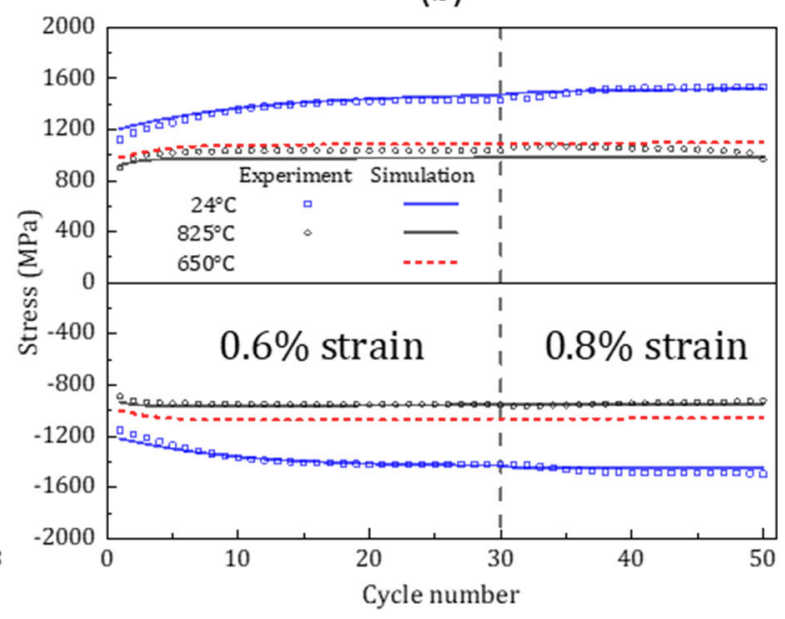

Fig. 6. Comparisons between the numerical and experimental results for the [111] orientation at $24{ }^{\circ} \mathrm{C}, 825^{\circ} \mathrm{C}$ and $650{ }^{\circ} \mathrm{C}$ : (a) the first hysteresis loop at $0.6 \%$ strain and (b) the stress evolution for $0.6 \%$ and $0.8 \%$ strain. 


\subsection{ICSS distribution around the crack tip}

By applying the $\mathrm{CP}$ model to the sample tested at room $\left(24^{\circ} \mathrm{C}\right)$ and high temperatures $\left(650^{\circ} \mathrm{C}\right)$, the ICSS value of each octahedral slip system at the crack tip was extracted before the first crack extension. Depending on the temperature, different slip systems were activated in the simulation, and the distinction among ICSS values can be significant. In Fig. 7, the ICSS values of all the octahedral slip systems in the $650{ }^{\circ} \mathrm{C}$ sample are provided in the form of contour plots. The produced fields for various slip systems differ significantly in both intensity and spatial distribution, showing asymmetric butterfly-shaped patterns around the tip. Comparing these plots, we deduce that the $(\overline{1} 11)[0 \overline{1} 1]$ and $(1 \overline{1} 1)[10 \overline{1}]$ slip systems were the most active near the crack tip, occupying the lower and the upper parts of the crack front respectively. In Fig. 8, the ICSS distributions in the $24{ }^{\circ} \mathrm{C}$ sample are displayed for the major slip systems. In fact, most of the slip systems were activated, but the slip only existed in a small region around the crack tip, which makes the ICSS pattern much smaller and less distinct. Similar to the $650{ }^{\circ} \mathrm{C}$ sample, the $(\overline{1} 11)[0 \overline{1} 1]$ and $(1 \overline{1} 1)[10 \overline{1}]$ slip systems were the most active near the crack tip, but narrow high-intensity zones could affect the crack propagation rate (as discussed in the next section). It is noted that the fields for the $650{ }^{\circ} \mathrm{C}$ sample are more dispersed than those for $24^{\circ} \mathrm{C}$ sample, which means that higher strain levels have been reached in a broader zone ahead of the crack tip in these samples. The distributions are expected to affect both the crack paths and propagation rates. In fact, a more scattered field indicated that a larger area will meet the critical value for crack growth. Also, areas dominated by different slip systems can result in competing crack paths and therefore increase or decrease the propagation rate. 


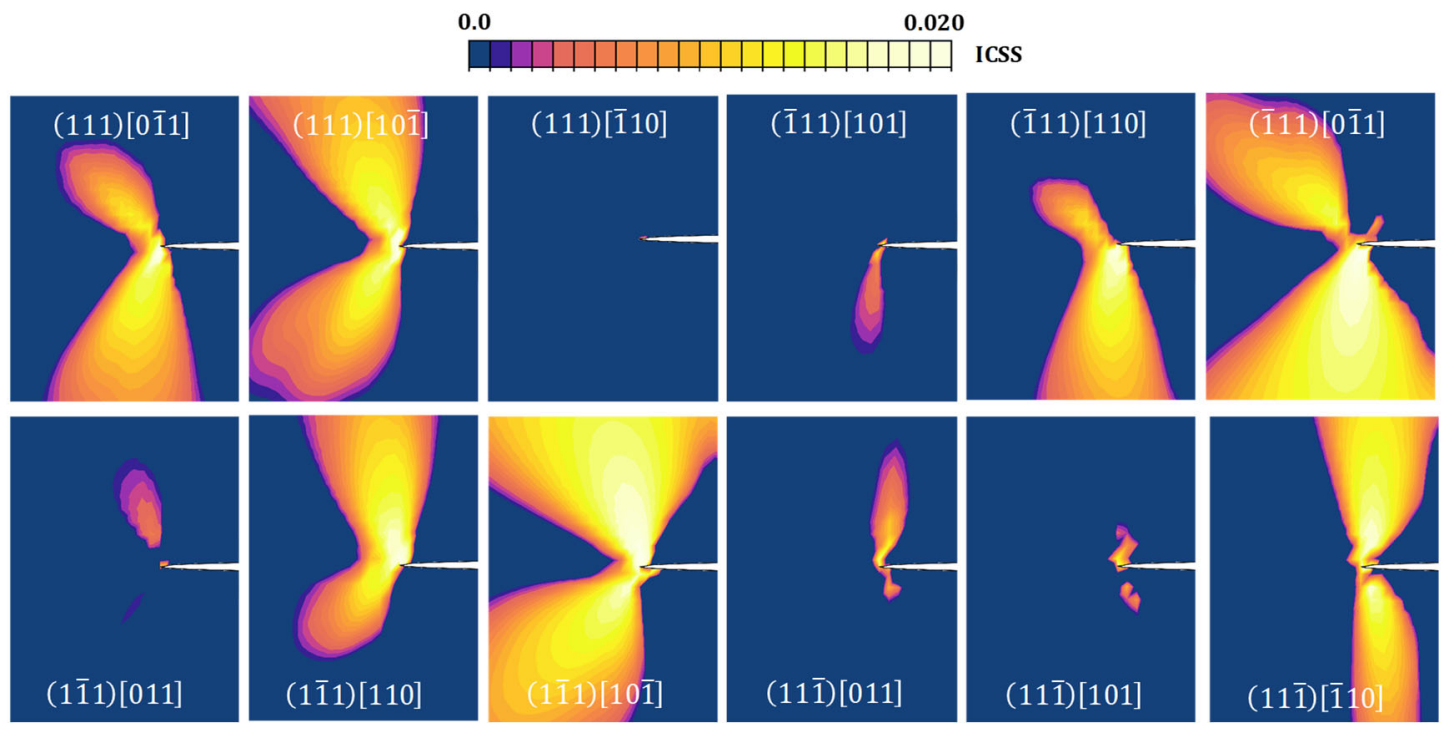

Fig. 7. ICSS distributions of octahedral slip systems around the crack tip in $650{ }^{\circ} \mathrm{C}$ sample

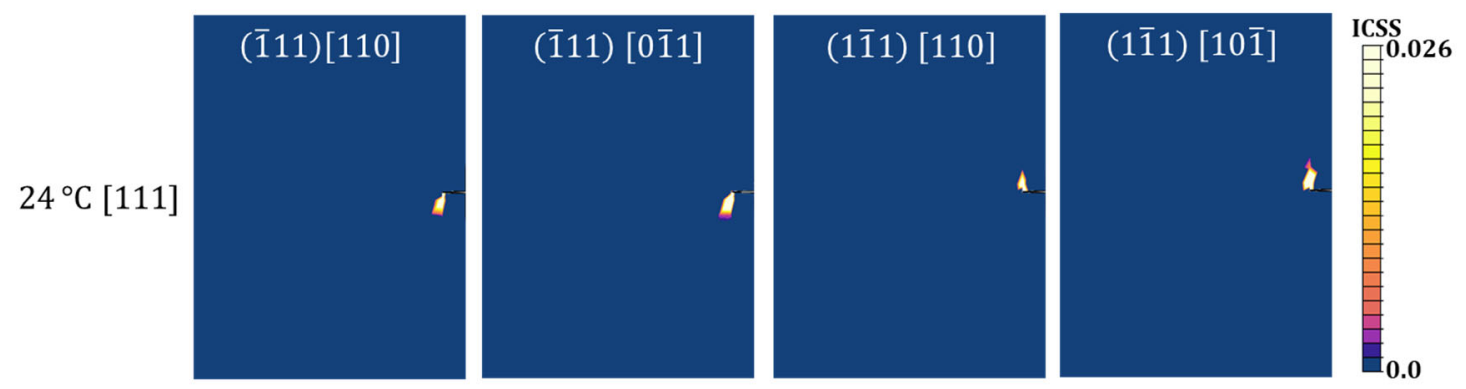

Fig. 8. ICSS distributions of major slip systems around the crack tip in $24{ }^{\circ} \mathrm{C}$ sample

\subsection{Crack propagation paths}

We now examine the crack propagation paths in both samples. Based on the earlier discussion regarding slip system activity, the Schmid factors and projected angles between crack extension direction and loading direction are provided in 
Table $\mathbf{2}$ as a reference. It should be noted that the local Schmid factor may be different because of the local stress distribution, nevertheless, it can explain the overall distinction among all octahedral slip systems.

The obtained numerical results for both samples are given in Fig. 9. It is clear that both the $24{ }^{\circ} \mathrm{C}$ and $650{ }^{\circ} \mathrm{C}$ samples exhibit a zig-zag crack behaviour comprising two types of crack paths, an upward path of $19.9^{\circ}$ or $27.4^{\circ}$ angle and a downward path of $154.3^{\circ}$ or $160.1^{\circ}$ angle, measured with respect to the loading axis. Hence, it is inferred from

Table 2 that the cracks are dominated by the slip systems of the ( $\overline{1} 11)$ and the $(1 \overline{1} 1)$ slip planes. It should be mentioned that the (111) [10ㅍ] slip system has an absolute Schmid factor value 0.2671 based on theoretical calculations, which is higher than any slip system of the (1111) slip plane family, however, the predicted path of $100.2^{\circ}$ angle was not found either in the experiment or in the numerical study. This manifests that the crack path is not only controlled by the overall Schmid factor but also affected by local stress distributions altered by the presence of the evolving crack. It should be noted that the mode I path observed for high temperature was predominantly related to the crack initiation stage. In this paper, we focused on the crack propagation stage which is controlled by crystallographic slip. Further research will be required in order to capture the crack path at the initiation stage, such as modifications of the crack growth criterion by including multiple slip behaviour.

Table 2. Schmid factors and crack path angles of octahedral slip systems for both samples.

\begin{tabular}{|l|l|l|}
\hline & $24^{\circ} \mathrm{C}[111]$ & $650^{\circ} \mathrm{C}[111]$ \\
\hline
\end{tabular}




\begin{tabular}{|c|c|c|c|c|c|c|}
\hline No. & Slip plane & Slip direction & Schmid factor & Crack path & Schmid factor & Crack path \\
\hline 1 & (111) & [0̄1] & 0.2556 & \multirow[t]{3}{*}{$100.2^{\circ}$} & 0.2460 & \multirow[t]{3}{*}{$86.3^{\circ}$} \\
\hline 2 & (111) & {$[10 \overline{1}]$} & -0.2671 & & -0.2293 & \\
\hline 3 & (111) & {$[\overline{1} 10]$} & 0.0114 & & -0.0166 & \\
\hline 4 & $(\overline{1} 11)$ & [101] & -0.0017 & \multirow{3}{*}{$154.3^{\circ}$} & 0.0218 & \multirow{3}{*}{$160.1^{\circ}$} \\
\hline 5 & $(\overline{1} 11)$ & [110] & -0.2983 & & -0.2420 & \\
\hline 6 & $(\overline{1} 11)$ & [0̄1] & 0.2966 & & 0.2637 & \\
\hline 7 & $(1 \overline{1} 1)$ & [011] & 0.0097 & \multirow[t]{3}{*}{$19.9^{\circ}$} & 0.0051 & \multirow[t]{3}{*}{$27.4^{\circ}$} \\
\hline 8 & $(1 \overline{1} 1)$ & [110] & -0.2510 & & -0.3164 & \\
\hline 9 & $(1 \overline{1} 1)$ & {$[10 \overline{1}]$} & -0.2607 & & -0.3216 & \\
\hline 10 & $(11 \overline{1})$ & [011] & 0.0312 & \multirow[t]{3}{*}{$88.0^{\circ}$} & 0.0127 & \multirow[t]{3}{*}{$93.2^{\circ}$} \\
\hline 11 & $(11 \overline{1})$ & [101] & -0.0046 & & 0.0705 & \\
\hline 12 & $(11 \overline{1})$ & [1]10] & 0.0359 & & -0.05783 & \\
\hline
\end{tabular}

Interestingly, the numerical response obtained for the $24{ }^{\circ} \mathrm{C}$ specimen has many similarities to the corresponding experimental observation (Fig. 9a). Indeed, the crack initiated in a complex pattern alternating between $20^{\circ}$ and $155^{\circ}$ and finished along a single upward path after an almost horizontal segment, which comprises small cracks facing either upwards or downwards. This trend is also observed in the numerical results as the crack initiates along a small tortuous path and ends with a larger scale triangular pattern. These two blocks are connected with a middle region that contains tiny deflections and flat segments, as an outcome of intensive com-

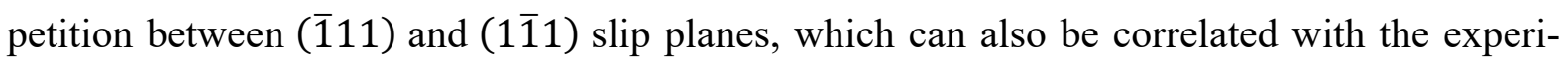
ment. Looking at the $\triangle \mathrm{ICSS}$ of the $24^{\circ} \mathrm{C}$ sample, which shows the difference of ICSS values between the last two crack growth increments, the higher intensity values are around the crack path and crack tip, reflecting the stress concentration. The ICSS will accumulate around the crack tip and drive the crack to grow further. 
However, there is a mismatch between experimental and numerical results regarding the amplitude of the propagating cracks. The crack path of $24{ }^{\circ} \mathrm{C}$ simulation showed a similar amplitude to the experimental result, while the numerical result of $650{ }^{\circ} \mathrm{C}$ shows a smaller amplitude than the experimental one. There are several reasons that may account for this mismatch: (1) This work did not take into account the effects of creep and oxidation at high temperature, which could change the local activities of slip systems, affecting the propagation of cracks. (2) The FE model in this work did not consider any defects contained in the specimens, such as voids and inclusions, which could have an impact on the crack growth path due to the alteration of local stresses and slip activities. (3) From experimental observations, multiple slip bands (slip traces) were formed ahead of the crack tip and also along the crack path (see Fig. 9). This phenomenon was not captured in our simulation and can also affect the actual crack path fluctuation. We believe that the formation of a slip-band network alters the local deformation states and acts as a mechanism of material damage and energy release. (4) The initiation stage of cracks was not modelled in this work and we simply introduced a predefined crack, which could also affect the slip-controlled crack growth path. 
(a) $24^{\circ} \mathrm{C}[111]$

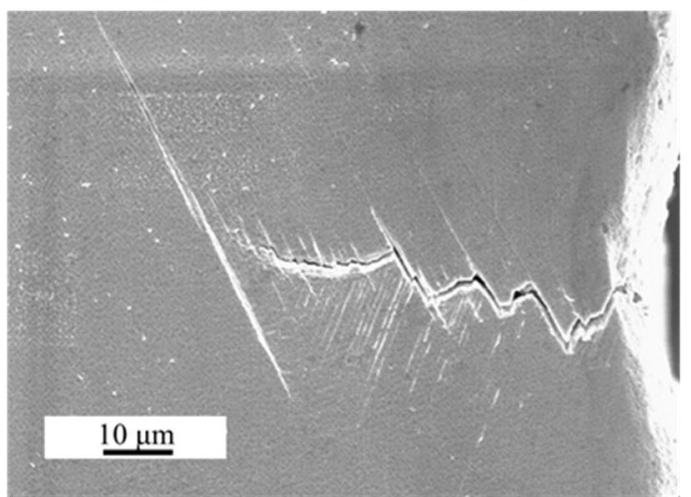

$\Delta \mathrm{ICSS}$

0.0

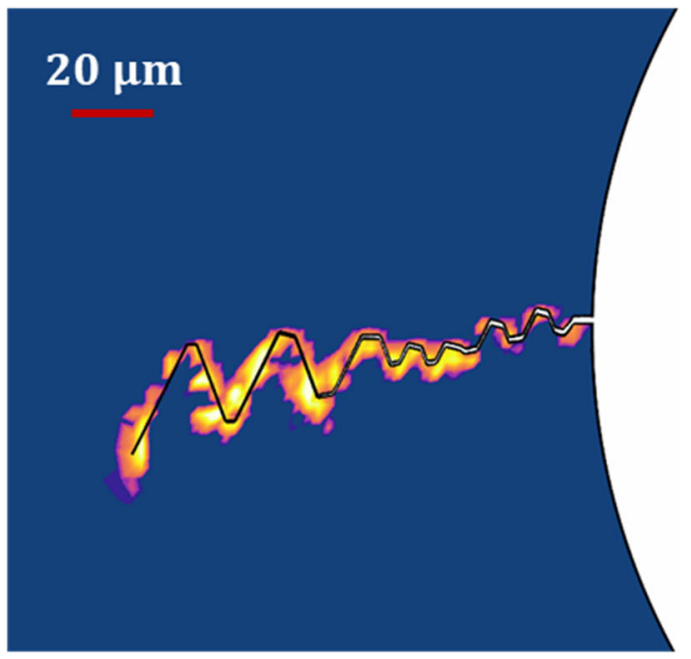

(b) $650{ }^{\circ} \mathrm{C}[111]$
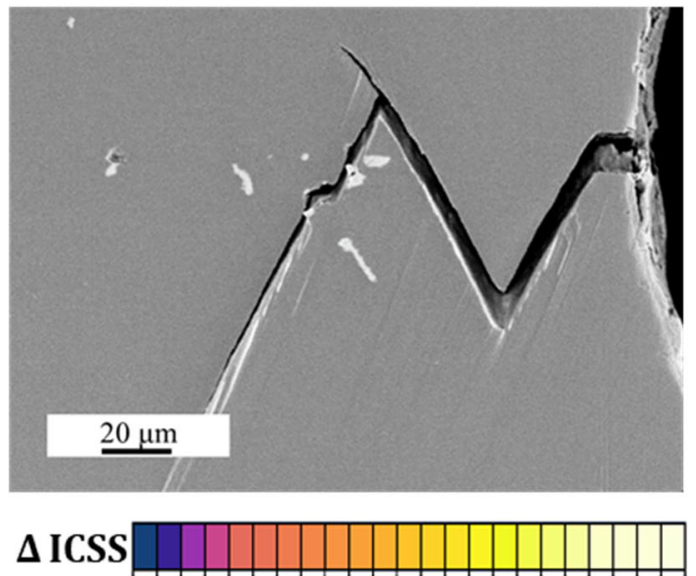

0.0

0.006

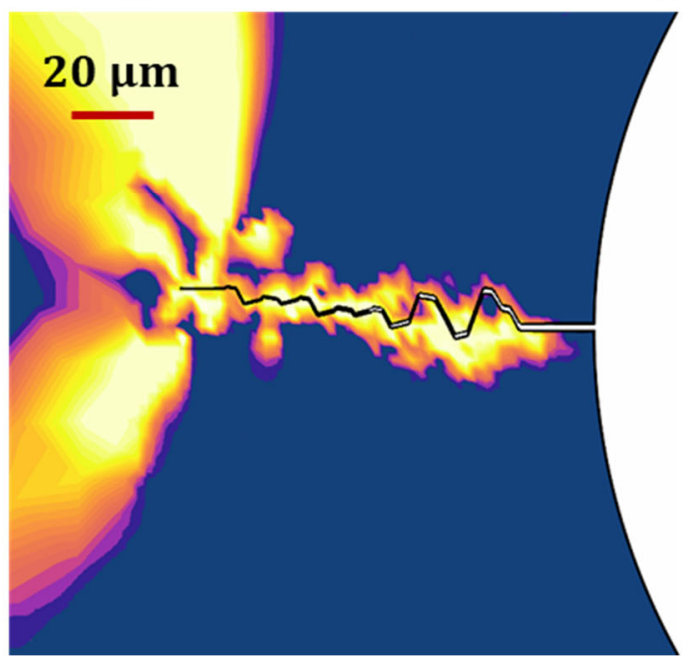

Fig. 9. Experimental and numerical crack paths for (a) $24{ }^{\circ} \mathrm{C}$ and (b) $650{ }^{\circ} \mathrm{C}$ samples.

Further, we analyse the evolution of ICSS values around the crack tip, in order to gain a better understanding on crack deflections with increasing loading cycles. In Fig. 10, a map of slip plane activity at certain loading cycles is depicted for the $24{ }^{\circ} \mathrm{C}$ specimen, showing the slip plane with the highest ICSS within each element. The four active slip planes are represented by different colours and the crack is expected to grow according to the dominant slip plane, i.e. the slip plane with the highest ICSS value, within each element. It is observed that the specimen is mainly dominated by two slip planes throughout the loading history, the $(\overline{1} 11)$ and the (1111) slip plane represented by green and blue colours, respectively. Starting from the $17^{\text {th }}$ 
cycle (Fig. 10a), the crack tip (point A) is at the boundary of two domains and about to change its direction. From the $17^{\text {th }}$ cycle to the $20^{\text {th }}$ cycle, the crack grows within the blue area along a $19.9^{\circ}$ upward direction and then reaches a border between the two slip planes (point B in Fig. 10b). After the $20^{\text {th }}$ cycle, the crack enters the green area controlled by the (111) slip plane and propagates downwards along the edge of this domain with an angle of $154.3^{\circ}$ (Fig. 10c). Then, at the $23^{\text {rd }}$ cycle, the crack deflects again (point C) and grows along the $19.9^{\circ}$ upward direction as it extends outside the (111) slip plane area (Fig. 10d).

(a) cycle 17

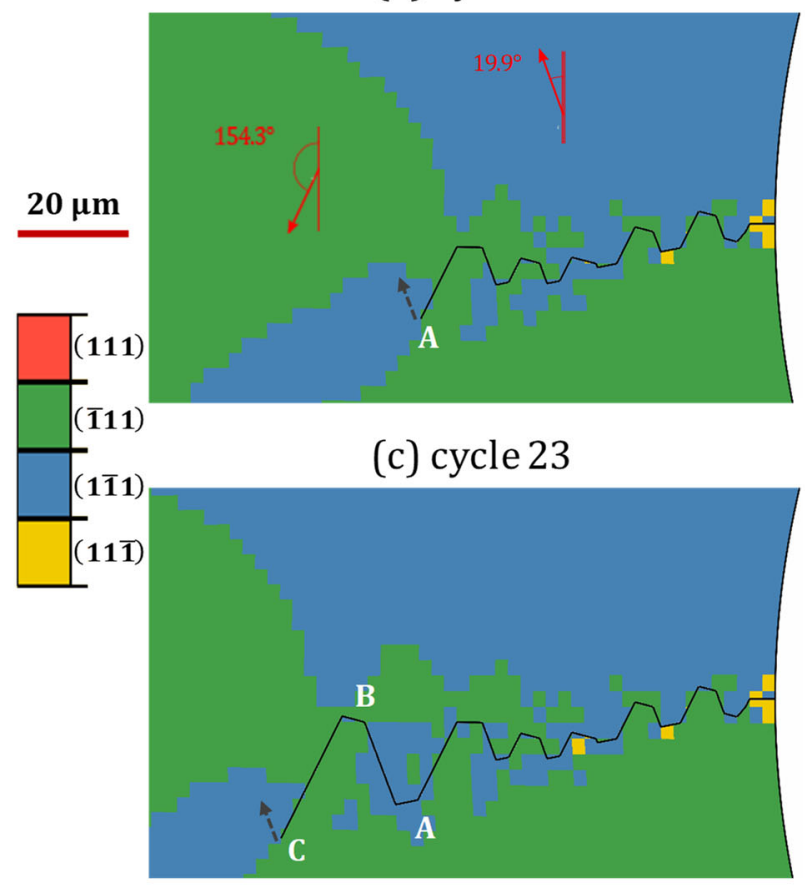

(b) cycle 20

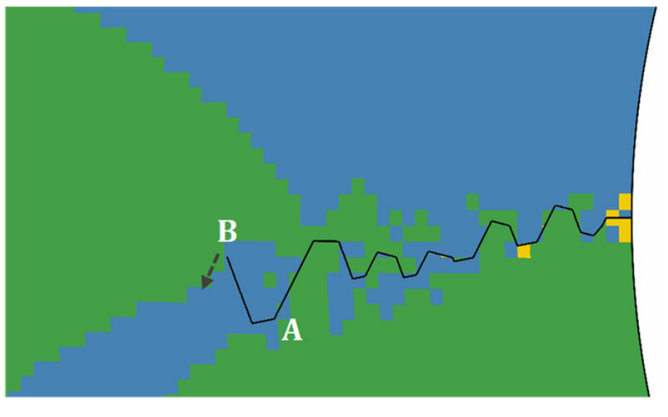

(d) cycle 25

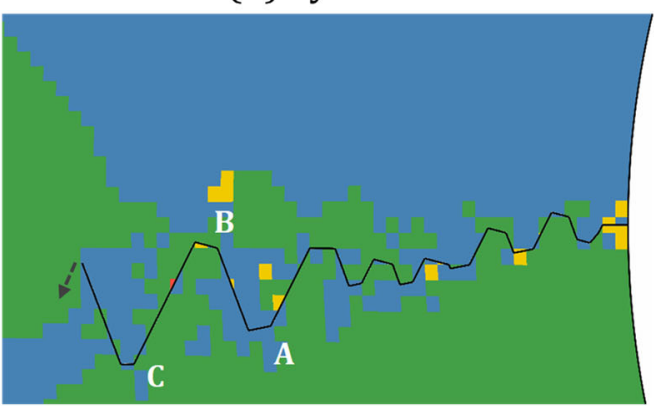

Fig. 10. Evolution of slip plane activity for the $24{ }^{\circ} \mathrm{C}$ sample with increasing loading cycles

Moreover, comparing the size and shape evolution of the two domains that form during the crack propagation, we see that the slip plane area ahead of the crack tip is pushed forward and its size diminishes as the crack grows. For instance, there is an obvious difference in the green area between the $20^{\text {th }}$ cycle and the $23^{\text {rd }}$ cycle. In general, the stress field due to the propagating crack alters the local activity of the two slip planes. More specifically, the crack tries to enlarge 
the domain to which it belongs in order to maintain its propagation direction. When this is not possible, a deflection is observed.

(a) cycle 1

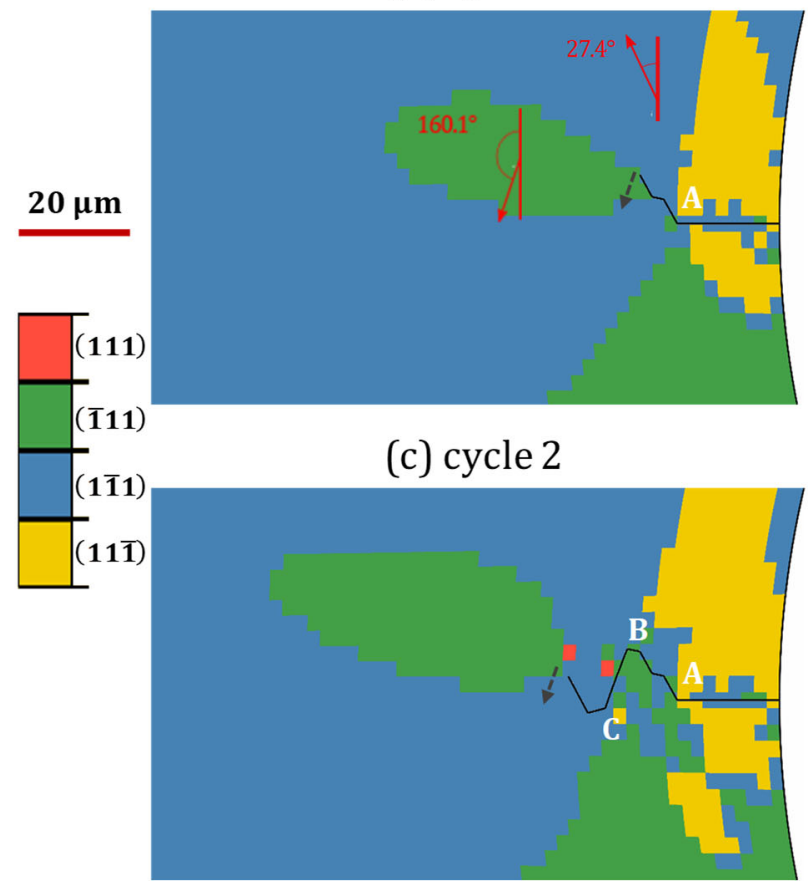

(b) cycle 1

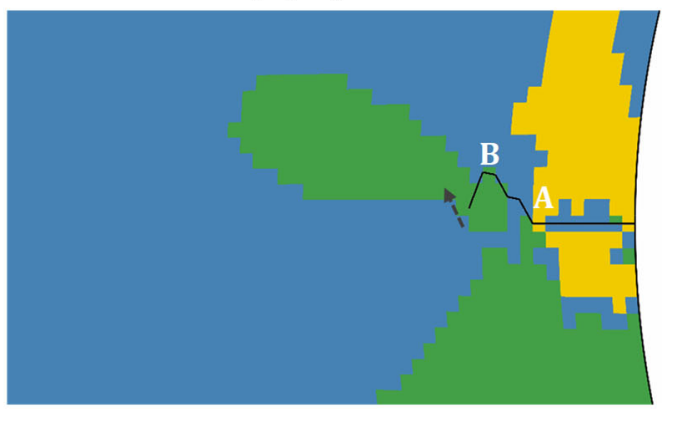

(d) cycle 5

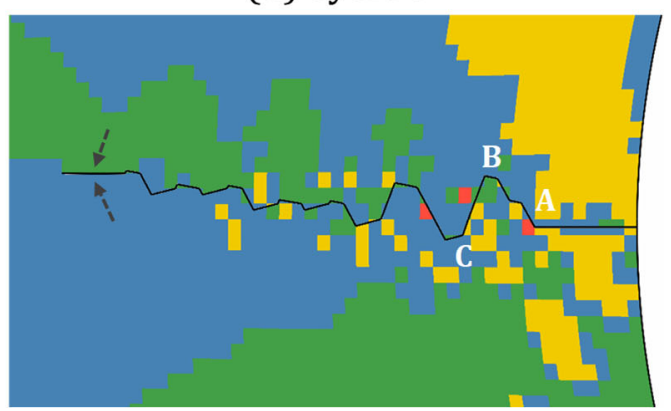

Fig. 11. Evolution of slip plane activity for the $650{ }^{\circ} \mathrm{C}$ sample with increasing loading cycles

On the other hand, the experimental result of the $650^{\circ} \mathrm{C}$ specimen (Fig. 9b) shows a simpler propagation path. In this case, the crack experienced two deflections and then shifted to a horizontal segment affected by some carbides. The numerical result follows a similar trend with the individual lengths of the deflecting paths being somewhat smaller in size. Looking at the $\triangle \mathrm{ICSS}$ distribution, the high-intensity area was much larger than that in the $24^{\circ} \mathrm{C}$ sample, especially around the crack tip. In accordance with the results in Fig. 7 and Fig. 8, the size of the slip intense zone could affect the propagation rate. To analyse the crack propagation response, we use again a map of slip plane activity at different loading cycles. In Fig. 11, we note that the specimen is now separated into three parts, the green part dominated by the (111) slip

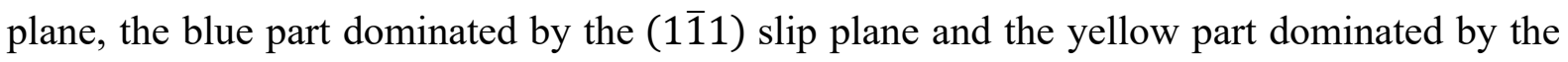


(11̄) slip plane. Before the first extension (Fig. 11a), the elements ahead of the crack tip (point A) with the highest ICSS values belonged to the (1111) slip plane, resulting thus in an upward crack path of $27.4^{\circ}$ (see also

Table 2). Then, the crack entered the area of the (111) slip plane and extended downwards along a $160.1^{\circ}$ angle (point B in Fig. 11b) followed again by an upward path caused by the (1111) slip plane (point $C$ in Fig. 11c). From the $2^{\text {nd }}$ to the $5^{\text {th }}$ cycle, the crack continued along altering directions as it entered different slip plane regions (Fig. 11d). The highly intense competition between the $(\overline{1} 11)$ and the $(1 \overline{1} 1)$ slip planes led to a nearly flat crack path, almost vertical to the loading direction (mode I). These results verify that the crack propagation is indeed slip controlled.

\subsection{Crack propagation rates}

Besides the crack propagation paths, it is important for any numerical technique to effectively capture the crack propagation rates. The numerical results of our investigation are presented in Fig. 12 for both temperatures. The experimental data are also added in this plot. It should be clarified that the number of numerical loading cycles has been scaled up by an averaged scale factor (1123) to enable a direct comparison with the experimental results, which was calculated by matching the number of cycles required for cracks to grow to a medium length $(\sim 50 \mu \mathrm{m})$ in experiments and simulations. Since crack propagation simulations are extremely time-consuming, it is not feasible to model the same number of loading cycles as in the experiment. This is the reason behind the scale factor. It should be noted that this factor is expected to affect the comparison. For instance, we could obtain a different scale factor by matching the simulated and experimental results at a different point of crack growth. In this study, the scale factor was obtained by matching the results at the middle point of total crack growth, and the purpose 
is solely to show the capability of CP-XFEM approach in capturing slip-controlled crack growth behaviour. As we introduced a predefined crack, the cycles before the crack propagation were not taken into account, and the first cycle of simulation was considered as the start of the crack propagation. Also, the crack paths were projected to the direction normal to the loading axis for crack length measurement since the propagation paths were not horizontal in most cases.

As shown in Fig. 12a, we notice that the numerical curves in this plot are not smooth but present a step change of shape with increasing loading cycles, exhibiting the same response as experimental results. This behaviour is attributed to the multiple deflected crack paths as discussed earlier. Further, we note that the cracks initiate earlier in the numerical simulations compared to the experimental data; however, the deviation is not significant. This is primarily caused by the introduction of a predefined crack, which increased the stress concentration around the crack tip. On the other hand, the overall trends of crack growth in the numerical simulations are consistent with the experiments, especially in the crack length region of $40 \mu \mathrm{m}$ to $110 \mu \mathrm{m}$. For the $650{ }^{\circ} \mathrm{C}$, a much smaller number of cycles is required to reach the specified crack length when compared to that for $24^{\circ} \mathrm{C}$. This is attributed to the higher critical damage value and a more concentrated area of high ICSS value for the $24{ }^{\circ} \mathrm{C}$ case, as well as the difference in the number of crack deflections. 
(a)

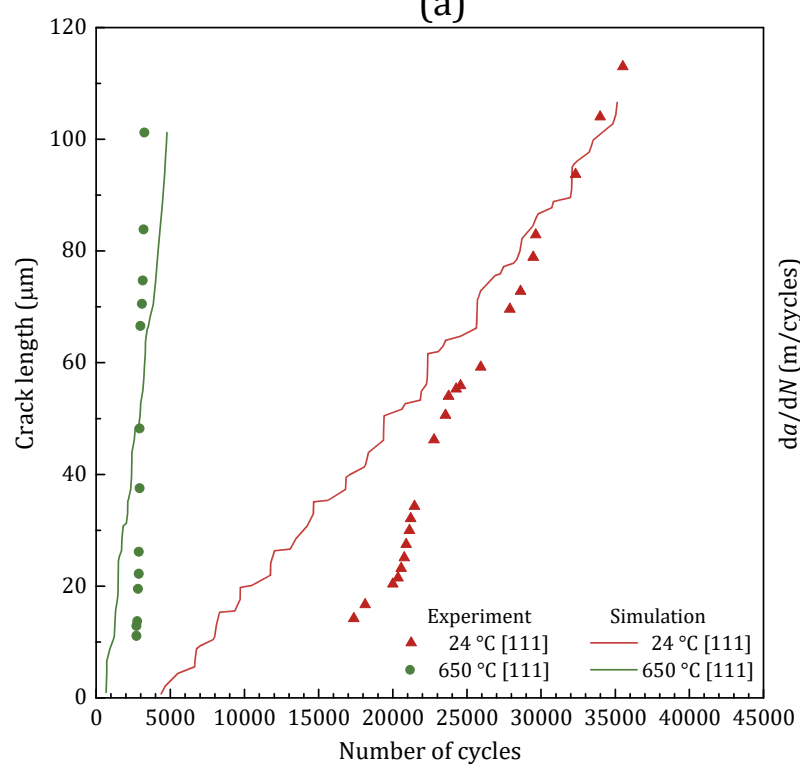

(b)

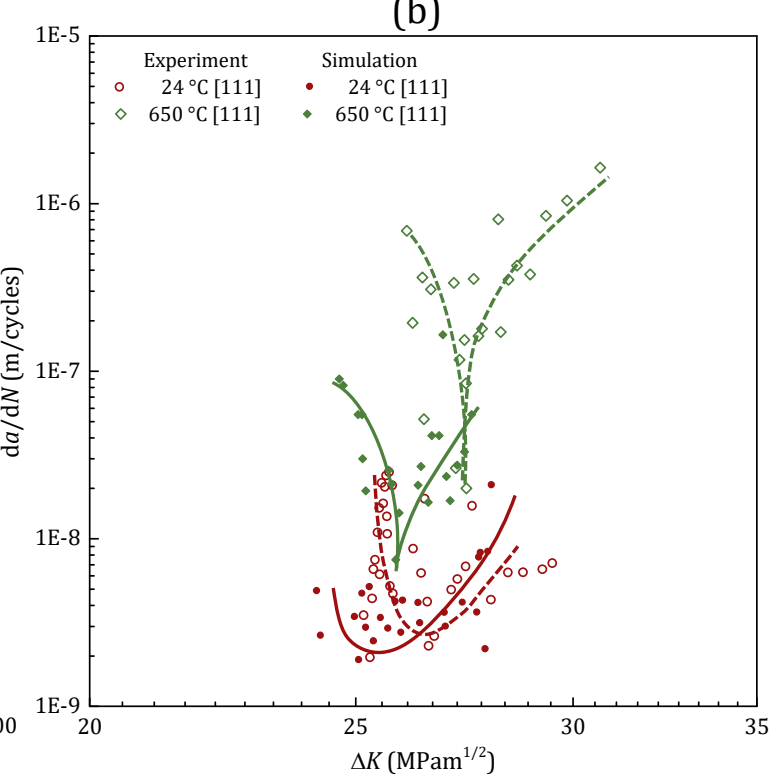

Fig. 12. Comparison of experimental results and numerical predictions for both specimens:

(a) crack length over the number of cycles and (b) effect of $\Delta K$ on crack propagation rate.

Meanwhile, the crack propagation rate was correlated to the range of stress intensity factor (SIF), as shown in Fig. 12b. The SIFs were calculated by following the formulas for a singleedge crack [43]. As shown in the figure, the fatigue crack propagation rates were highly related to the temperature. Numerical results are lower than the experimental ones, which may be caused by the reasons discussed in Section 4.3. In addition, the critical ICSS values used in this study were not obtained from experiments and the choice was largely based on the consideration of computing times. As a result, a scaling factor was used in order to compare the XFEMpredicted crack growth rates with the in-situ SEM measurements, which would introduce an inevitable mismatch to the comparison. But the results show the same trend as observed in the experiments, i.e., a deceleration followed by an acceleration in the crack growth rate. On the other hand, higher growth rates were obtained for $650^{\circ} \mathrm{C}$, which can be attributed to the lower yield stress as well as the reduced critical damage value for the sample tested at $650{ }^{\circ} \mathrm{C}$. 
The XFEM implemented in ABAQUS has the ability to simulate both crack initiation and subsequent crack growth (i.e. without a predefined crack). But in this work, we are more focused on slip-controlled crack growth as observed for both room and high temperatures. Nevertheless, the current work is a step forward to model slip-controlled short crack growth using a more physical approach, i.e. CP and ICSS criterion, and further research would be required in order to improve the prediction of crack growth path and rate, including crack initiation stage.

\section{Conclusions}

A computational model comprising CP and XFEM was employed in this study to evaluate the short crack propagation in a Ni-based single crystal superalloy. The adopted damage criterion described crack growth along the slip system with the highest cumulative shear strain. Based on this assumption, the experimentally observed tortuous crack paths were captured. Details of crack deflections were further explained by tracking the evolution of slip plane activity, showing the competition, development and alternation of slip planes in controlling the crack propagation. Moreover, the crack propagation rates and the effect of $\Delta K$ for both samples were recovered in the model. The numerical approach looks promising for the evaluation of short crack propagation; However, there are still some limitations regarding the computational cost and the use of XFEM in predicting cracks with sharp deflection. Further improvement could be made by taking into account the effects of oxidation, defects and slip bands to better capture the crack growth path and rate. In conclusion, this research contributes to the understanding of short crack propagation and allows for further modifications to describe the evolution mechanism of this complex and challenging phenomenon.

\section{Acknowledgements}


P. Zhang would like to acknowledge the support from the China Scholarship Council (CSC, No. 201806290092). The work was also funded by the EPSRC (Grant EP/M000966/1 and $\mathrm{EP} / \mathrm{K} 026844 / 1)$ of the UK and in collaboration with GE Power, Rolls-Royce and dstl. The authors are highly grateful to Prof Changqing Chen and Dr Manqiong Xu (Tsinghua University of China) for their support of in-situ crack growth experiments in their laboratory.

\section{References}

[1] Connolley T, Reed PAS, Starink MJ. Short crack initiation and growth at $600^{\circ} \mathrm{C}$ in notched specimens of Inconel718. Mater Sci Eng A 2003;340:139-54. doi:https://doi.org/10.1016/S0921-5093(02)00169-7.

[2] Toh SF, Rainforth WM. Fatigue of a nickel base superalloy with bimodal grain size. Mater Sci Technol 1996;12:1007-14. doi:10.1179/026708396790121946.

[3] Ma X, Shi HJ. In situ SEM studies of the low cycle fatigue behavior of DZ4 superalloy at elevated temperature: Effect of partial recrystallization. Int J Fatigue 2014;61:25563. doi:10.1016/j.ijfatigue.2013.11.001.

[4] Henderson MB, Martin JW. The influence of crystal orientation on the high temperature fatigue crack growth of a Ni-based single crystal superalloy. Acta Mater 1996;44:111-26. doi:10.1016/1359-6454(95)00147-9.

[5] Joyce MR, Wu X, Reed PAS. The effect of environment and orientation on fatigue crack growth behaviour of CMSX-4 nickel base single crystal at $650{ }^{\circ} \mathrm{C}$. Mater Lett 2004;58:99-103. doi:10.1016/S0167-577X(03)00423-3.

[6] Ma X, Shi H, Gu J, Wang Z, Harders H, Malow T. Temperature effect on low-cycle fatigue behavior of nickel-based single crystalline superalloy. Acta Mech Solida Sin 2008;21:289-97. doi:10.1007/s10338-008-0833-2.

[7] Neu RW. Crack paths in single-crystal Ni-base superalloys under isothermal and 
thermomechanical fatigue. Int J Fatigue 2019;123:268-78.

doi:10.1016/j.ijfatigue.2019.02.022.

[8] Zhang L, Zhao LG, Roy A, Silberschmidt VVV, McColvin G. In-situ SEM study of slip-controlled short-crack growth in single-crystal nickel superalloy. Mater Sci Eng A 2019;742:564-72. doi:10.1016/j.msea.2018.11.040.

[9] Krueger R. Virtual crack closure technique: History, approach, and applications. Appl Mech Rev 2004;57:109-43. doi:10.1115/1.1595677.

[10] Elices M, Guinea G V., Gómez J, Planas J. The cohesive zone model: Advantages, limitations and challenges. Eng Fract Mech 2001;69:137-63. doi:10.1016/S00137944(01)00083-2.

[11] Li H, Li J, Yuan H. A review of the extended finite element method on macrocrack and microcrack growth simulations. Theor Appl Fract Mech 2018;97:236-49. doi:10.1016/j.tafmec.2018.08.008.

[12] Moës N, Dolbow J, Belytschko T. A finite element method for crack growth without remeshing. Int J Numer Methods Eng 1999;46:131-50. doi:10.1002/(SICI)10970207(19990910)46:1<131::AID-NME726>3.0.CO;2-J.

[13] Rannou J, Limodin N, Réthoré J, Gravouil A, Ludwig W, Baïetto-Dubourg MC, et al. Three dimensional experimental and numerical multiscale analysis of a fatigue crack. Comput Methods Appl Mech Eng 2010;199:1307-25. doi:10.1016/j.cma.2009.09.013.

[14] Cuadra J, Baxevanakis KP, Loghin A, Kontsos A. Validation of a cyclic plasticity computational method using fatigue full-field deformation measurements. Fatigue Fract Eng Mater Struct 2016;39:722-36. doi:10.1111/ffe.12396.

[15] Farukh F, Zhao LG, Jiang R, Reed P, Proprentner D, Shollock BA. Realistic microstructure-based modelling of cyclic deformation and crack growth using crystal plasticity. Comput Mater Sci 2016;111:395-405. 
doi:10.1016/j.commatsci.2015.09.054.

[16] Vajragupta N, Uthaisangsuk V, Schmaling B, Münstermann S, Hartmaier A, Bleck W. A micromechanical damage simulation of dual phase steels using XFEM. Comput Mater Sci 2012;54:271-9. doi:10.1016/j.commatsci.2011.10.035.

[17] Wells GN, Sluys LJ. A new method for modelling cohesive cracks using finite elements. Int J Numer Methods Eng 2001;50:2667-82. doi:10.1002/nme.143.

[18] Sukumar N, Moës N, Moran B, Belytschko T. Extended finite element method for three-dimensional crack modelling. Int J Numer Methods Eng 2000;48:1549-70. doi:10.1002/1097-0207(20000820)48:11<1549::AID-NME955>3.0.CO;2-A.

[19] Sukumar N, Srolovitz DJ, Baker TJ, Prévost JH. Brittle fracture in polycrystalline microstructures with the extended finite element method. Int J Numer Methods Eng 2003;56:2015-37. doi:10.1002/nme.653.

[20] Cuadra JA, Baxevanakis KP, Mazzotti M, Bartoli I, Kontsos A. Energy dissipation via acoustic emission in ductile crack initiation. Int J Fract 2016;199:89-104. doi:10.1007/s10704-016-0096-8.

[21] Roters F, Eisenlohr P, Hantcherli L, Tjahjanto DD, Bieler TR, Raabe D. Overview of constitutive laws, kinematics, homogenization and multiscale methods in crystal plasticity finite-element modeling: Theory, experiments, applications. Acta Mater 2010;58:1152-211. doi:10.1016/j.actamat.2009.10.058.

[22] McDowell DL, Dunne FPE. Microstructure-sensitive computational modeling of fatigue crack formation. Int J Fatigue 2010;32:1521-42. doi:https://doi.org/10.1016/j.ijfatigue.2010.01.003.

[23] Carroll JD, Abuzaid W, Lambros J, Sehitoglu H. High resolution digital image correlation measurements of strain accumulation in fatigue crack growth. Int J Fatigue 2013;57:140-50. doi:10.1016/j.ijfatigue.2012.06.010. 
[24] Zhao LG, Tong J. A viscoplastic study of crack-tip deformation and crack growth in a nickel-based superalloy at elevated temperature. J Mech Phys Solids 2008;56:336378. doi:10.1016/j.jmps.2008.09.006.

[25] Lin B, Zhao LG, Tong J. A crystal plasticity study of cyclic constitutive behaviour, crack-tip deformation and crack-growth path for a polycrystalline nickel-based superalloy. Eng Fract Mech 2011;78:2174-92. doi:10.1016/j.engfracmech.2011.04.006.

[26] Zhang K, Wu X, Davies CHJ. Effect of microtexture on short crack propagation in two-phase titanium alloys. Int J Fatigue 2017;104:206-20. doi:10.1016/j.ijfatigue.2017.07.022.

[27] Proudhon H, Li J, Wang F, Roos A, Chiaruttini V, Forest S. 3D simulation of short fatigue crack propagation by finite element crystal plasticity and remeshing. Int $\mathbf{J}$ Fatigue 2016;82:238-46. doi:10.1016/j.ijfatigue.2015.05.022.

[28] Li J, Proudhon H, Roos A, Chiaruttini V, Forest S. Crystal plasticity finite element simulation of crack growth in single crystals. Comput Mater Sci 2014;94:191-7. doi:10.1016/j.commatsci.2014.03.061.

[29] Proudhon H, Li JJ, Ludwig W, Roos A, Forest S. Simulation of Short Fatigue Crack Propagation in a 3D Experimental Microstructure. Adv Eng Mater 2017;19:8. doi:10.1002/adem.201600721.

[30] Wilson D, Dunne FPE. A mechanistic modelling methodology for microstructuresensitive fatigue crack growth. J Mech Phys Solids 2019;124:827-48. doi:10.1016/j.jmps.2018.11.023.

[31] Wilson D, Wan W, Dunne FPE. Microstructurally-sensitive fatigue crack growth in HCP, BCC and FCC polycrystals. J Mech Phys Solids 2019;126:204-25. doi:10.1016/j.jmps.2019.02.012. 
[32] Asaro RJ, Rice JR. Strain localization in ductile single crystals. J Mech Phys Solids 1977;25:309-38. doi:10.1016/0022-5096(77)90001-1.

[33] Peirce D, Asaro RJ, Needleman A. An analysis of nonuniform and localized deformation in ductile single crystals. Acta Metall 1982;30:1087-119. doi:10.1016/0001-6160(82)90005-0.

[34] Rice JR. Inelastic constitutive relations for solids: An internal-variable theory and its application to metal plasticity. J Mech Phys Solids 1971;19:433-55. doi:10.1016/0022-5096(71)90010-X.

[35] Hutchinson JW. Bounds and Self-Consistent Estimates for Creep of Polycrystalline Materials. Proc R Soc A Math Phys Eng Sci 1976;348:101-27. doi:10.1098/rspa.1976.0027.

[36] Asaro RJ. Micromechanics of Crystals and Polycrystals. Adv Appl Mech 1983;23:1115. doi:10.1016/S0065-2156(08)70242-4.

[37] Frederick CO, Armstrong PJ. A mathematical representation of the multiaxial Bauschinger effect. Mater High Temp 2007;24:1-26. doi:10.3184/096034007X207589.

[38] Simulia D. Abaqus(2018) User's Manual. Provid RI, USA DS SIMULIA Corp 2018.

[39] Huang Y. A User-Material Subroutine Incorporating Single Crystal Plasticity in the ABAQUS Finite Element Program. Mech Rep 1781991.

[40] Moës N, Belytschko T. Extended finite element method for cohesive crack growth. Eng Fract Mech 2002;69:813-33. doi:10.1016/S0013-7944(01)00128-X.

[41] MacLachlan DW, Wright LW, Gunturi S, Knowles DM. Constitutive modelling of anisotropic creep deformation in single crystal blade alloys SRR99 and CMSX-4. Int. J. Plast., vol. 17, 2001, p. 441-67. doi:10.1016/S0749-6419(00)00058-9.

[42] American Society for Testing and Materials. Standard practice for strain-controlled 
fatigue testing, E606-04. ASM International: The Materials Information Society 2004.

[43] Tada H, Paris P, Irwin G. The stress analysis of cracks handbook: by Hiroshi Tada, with the cooperation of Paul C. Paris and George R. Irwin 1985. 